\title{
The implied internal rate of return in conventional residual valuations of development sites
}

Article

Accepted Version

Crosby, N., Devaney, S. and Wyatt, P. (2018) The implied internal rate of return in conventional residual valuations of development sites. Journal of Property Research, 35 (3). pp. 234-251. ISSN 1466-4453 doi:

https://doi.org/10.1080/09599916.2018.1457070 Available at https://centaur.reading.ac.uk/76231/

It is advisable to refer to the publisher's version if you intend to cite from the work. See Guidance on citing.

To link to this article DOI: http://dx.doi.org/10.1080/09599916.2018.1457070

Publisher: Routledge

All outputs in CentAUR are protected by Intellectual Property Rights law, including copyright law. Copyright and IPR is retained by the creators or other copyright holders. Terms and conditions for use of this material are defined in the End User Agreement.

www.reading.ac.uk/centaur 
Central Archive at the University of Reading

Reading's research outputs online 
The implied internal rate of return in conventional residual valuations of development sites

Neil Crosby, Steven Devaney, Peter Wyatt

Department of Real Estate and Planning

Henley Business School

University of Reading

\begin{abstract}
Explicit discounted cash flow methods are used in many countries to assess the value of real estate investments or their likely rate of return given a particular price. These are typically supplemented by simpler models for the purpose of estimating market value, leading to debate about different approaches. A parallel situation exists in the case of UK development sites: both cash flow appraisals and simpler residual valuations are used to assess site values. Yet debate here has been limited, even though traditional residual valuations involve steps that depart from project appraisal practices used in mainstream capital budgeting. We explore the relationship between the profit and interest allowances used in traditional residual valuations and the internal rates of return that they appear to imply. Published residual valuations typically allow for profit through use of a simple proportionate relationship between required profit and the cost or final value of a scheme. They also show limited variation in their profit assumptions, but this implies large differences in expected IRRs. Simulated examples then illustrate the implications of applying standard profit-on-cost rates to schemes of different lengths and with different levels of land value. Findings for project duration, in particular, are noteworthy since they indicate that lower IRRs are implied for longer projects, though this relationship is not necessarily rational.
\end{abstract}

\title{
Key Words
}

Internal rate of return, development, valuation, residual method, developer's profit

\section{Word Count}

7,837 words 


\section{The implied internal rate of return in conventional residual valuations of development sites}

\section{Introduction}

Little is known regarding either the expected or achieved rates of return for property development schemes. This lack of transparency is in contrast to the situation for investment properties where the formation of target return rates has been explored (see Crosby et al., 2016; Hutchison et al., 2017). For investment properties, data on yields from transactions allows expected rates of return to be inferred if they are not disclosed explicitly. Meanwhile, achieved rates of return for property investments at country, sector and segment level are published by MSCI for many mature real estate markets, based on the holdings of large institutional investors. This enables investors to benchmark the expected returns from real estate investments against either the achieved or expected returns from other investment properties, portfolios or markets. This comparison is normally undertaken against consistent measurement protocols using internal rates of return based on a number of approaches (for example, risk free rate plus risk premium) (Hutchison et al. 2017). For development schemes, though, there is little information of this nature because schemes are fewer in number, more heterogeneous and carried out by a diverse range of participants. Many participants in real estate development are not formally benchmarked and academic investigation of how developers form required rates of return is limited.

In the UK, a study of the financial performance of development schemes by IPD (2010) revealed wide dispersion and high cyclical sensitivity in outturn performance metrics based on a sample of schemes undertaken by institutional investors. This is unsurprising given that returns from property development will vary depending on the nature, location and timing of each scheme. However, the study was conducted against a backdrop of not knowing what the rates of return for development should be. Developers expect to receive a return for enterprise and risk, but the way that this return is expressed, both at the beginning and end of a project, varies. Cash markups on cost or value are frequently used, and internal rates of return are sometimes stated as well. The use of different metrics can make it harder to decide which development schemes are more viable or profitable.

Methods vary in how they account for the developer's return depending upon the application of technique. Previous research has identified extensive use of residual valuation techniques (Coleman, et al, 2012) and this is embedded in planning policy and practice guidance in the UK. Methods will potentially vary depending upon the magnitude of the development and the role of the particular appraisal. This in turn may be determined by the timing of the appraisal within the development process. A valuation to identify site value may be very different to a later appraisal to determine profit based on financing. Where the residual is the site value, profit levels are an input. In the current UK planning regime, planning obligations have become the residual which also requires profit levels as an input. Where more sophisticated cash flow models are used, possibly later in the process to determine profit as an outcome, there needs to be some benchmark for what is an acceptable level of profit.

Where residual valuations are used in the UK to estimate land value, they tend to specify return as a cash sum linked to either the total cost or total value of the proposed scheme. Rules of thumb are applied when specifying the proportion of value or cost set aside as return, but such rules may be insensitive to the scale of the project or the time frame involved. If discounted cash flow (DCF) appraisal is used instead, the return is expressed as a target rate per period. The issue then becomes that of gauging the appropriate rate. Yet the application of DCF in development appraisal can depart from standard corporate finance practice, particularly with regard to how debt finance is dealt with (Coleman et al., 2012). Some approaches used in UK 
practice have involved discounting at a finance rate and including a profit allowance as a cash sum within the cash flow. Almost universally, a contingency allowance is incorporated into cash flows and this is, arguably, no more than additional risk-adjusted return to the developer.

In this context, this paper investigates the relationship between expected profit mark-ups that are commonly used in practice (specifically profit on cost and profit on value) and the internal rate of return (IRR) that such mark-ups appear to imply. This is done by modelling developer returns for a set of hypothetical schemes and scenarios. Published data (on values, costs and other input variables) are used to set parameters for the model inputs, focusing on the ratio between development cost and value, the cost of finance and the duration of the scheme. The aim is to improve understanding of the form, extent and variability of developer returns with particular attention to expected return rates implied by traditional residual valuations of development land. The paper focuses on the UK real estate development market, but the findings will be relevant for other countries where similar appraisal methods are used or where cash-based performance metrics predominate.

\section{Literature review}

There is an extensive literature in the field of corporate finance that relates to project appraisal techniques and decision rules. Textbooks routinely advocate the use of DCF appraisal and net present value (NPV) based decision rules for evaluating potential investments. Surveys such as Graham and Harvey (2001) suggest that DCF techniques are widely used in practice, and that both NPV and IRR are referred to during project evaluation. They find that other performance metrics such as payback period are also considered. DCF techniques require target rates of return to be set and formal approaches for doing this exist. A firm's weighted average cost of capital (WACC) is a major reference point and the Capital Asset Pricing Model (CAPM) provides a further technique for deriving a target rate of return from first principles. Use of CAPM involves being able to identify an expected market return rate and how sensitive project cash flows will be to shifts in that market return rate. Meanwhile, Cornell (1999) discusses the impact of duration on risk, building off the work of Campbell and Mei (1993), and identifies that firms might rationally choose to discount longer projects at higher rates of return.

There are few sources of information on target or going-in IRRs for real estate investment activity. Hutchison et al. (2017) recently surveyed UK and international property investors about their investment appraisal practices. This study found widespread use of DCF approaches, but a more marked preference for IRR as the main decision metric as well as quite varied practices in regard to setting the target rates against which IRRs might be judged. Some organisations referred to their WACC, others to target rates based on stakeholder demands and competitive pressures, and others to the summation of a risk free rate and a qualitative risk premium for the asset in question. Such estimates can be cross-checked against the historical performance of real estate markets and assets. The study did not consider development schemes in depth, but it was noted that the approach to such schemes varied from that used for property investments. Typically, an absolute hurdle rate or profit margin was set for developments, and this rate did not seem to vary across markets or time.

Clayton et al. (2009) reported required unlevered IRRs across nine categories of commercial real estate investment that ranged from 10.2\% and 12.5\% between 1996Q1 and 2007Q2. The data are from the Real Estate Research Corporation's Real Estate Report, which publishes results from a quarterly survey of a sample of institutional investors and managers in the US. A more recent issue of this survey shows IRRs ranging from $7.9 \%$ to $10.2 \%$ between $2005 \mathrm{Q} 1$ and 2015Q1 across all property types. Similarly, Price Waterhouse Coopers conduct a quarterly 'Real Estate Investor Survey' which reports target IRRs for the main commercial and residential investment classes. For 2017Q3 these ranged between $8 \%$ and $9.77 \%$ for the key CBD and 
suburban real estate markets in the US. However, similar data for development schemes appears not to be published regularly.

Focusing on development, not only is empirical data difficult to find, but there is little theoretical discussion of developer returns in academic literature. It might be that setting an appropriate target rate should be seen simply as an extension of techniques applied to property investments or to other types of capital-intensive project. For example, Brown and Matysiak (2000) discuss risk grouping, risk ratios, CAPM, arbitrage pricing theory and WACC as ways of assessing the target rate of return. Yet it is clear that estimating a required IRR for development opportunities using some of these approaches requires data that might not exist or assumptions that are difficult to verify in a property development context.

One obstacle is that little is known about the performance of development schemes in general, 1 while each specific scheme represents the creation of a new asset with no prior cash flow and with highly individual features around the site, process and intended end product. Nonetheless, Geltner and Miller (2000) stress that, although difficult, estimating a required rate of return is an unavoidable element of all project evaluations and inherent to the process. They suggest a number of possible approaches; use historical return data from listed property development companies, use real option pricing to devise a suitable rate, or use a 'reinterpreted' WACC. For the latter approach, they argue that a development represents a long position in property of the type being developed and a short position in a loan to cover construction costs. They suggest that target rate, $E\left[r_{C}\right]$, should be a function of returns for that property type, $E\left[r_{v}\right]$, returns on lending, $E\left[r_{D}\right]$, and the relationship between finished value $(V)$ and costs $(K)$, referred to as the leverage ratio, LR. Mathematically:

$$
\mathrm{E}\left[\mathrm{r}_{\mathrm{C}}\right]=\mathrm{E}\left[\mathrm{r}_{\mathrm{D}}\right]+\mathrm{LR}\left(\mathrm{E}\left[\mathrm{r}_{\mathrm{V}}\right]-\mathrm{E}\left[\mathrm{r}_{\mathrm{D}}\right]\right)
$$

Where $\mathrm{LR}$ is the leverage ratio $\mathrm{V} /(\mathrm{V}-\mathrm{K})$. This is a WACC-style calculation. For example, if $\mathrm{V}=$ $4.6 \mathrm{~m}$ and $\mathrm{K}=3.8 \mathrm{~m}$ then $\mathrm{LR}=(4.6 / 0.8)=5.75$, and if $\mathrm{E}\left[\mathrm{r}_{\mathrm{D}}\right]=10 \%$ and $\mathrm{E}\left[\mathrm{r}_{\mathrm{V}}\right]=11 \%$ :

$$
\mathrm{E}\left[\mathrm{r}_{\mathrm{C}}\right]=0.1+5.75 \times 0.01=0.1575 \text { or } 15.75 \%
$$

In contrast, traditional development appraisal techniques used in the UK have been based around a residual approach where expected costs are deduced from expected revenues, and where required profit is treated as a cash sum proportional to either development costs or expected scheme value. Simple adjustments for timing then involve discounting at a debt interest rate rather than at a target rate. These practices have been reviewed in depth by Coleman et al. (2012) who conclude that the residual method as conventionally applied is inconsistent with capital budgeting principles. However, application of the traditional residual approach may be able to approximate the outcomes of more sophisticated techniques if market participants adjust the required profit sum in ways that mirror how target rates might be changed for projects with different attributes. ${ }^{2}$ The next section of this paper investigates whether or not this is the case in the UK context.

This study complements a growing literature on the application of development appraisal techniques to financial viability appraisal in the English planning system, in which both policy issues and technical issues are raised. For instance, McAllister et al. (2013) and Crosby et al. (2013) investigate the application and use of development viability models in the formation of planning policies. They find that, although development viability models have intrinsic

\footnotetext{
${ }^{1}$ The study by IPD (2010) is an exception, but this study is not widely available and is no longer updated. ${ }^{2}$ McDonald (cited in Graham and Harvey, 2001) suggests that this might particularly hold for projects where cash flows are very uncertain and possess option-like features, as would be the case for many property development schemes.
} 
limitations associated with model composition and input uncertainties, the most significant limitation is related to the ways in which they have been adapted for use in the planning system. Developing this theme, McAllister et al. (2015) argue that the increased use of financial viability appraisals in planning raises important questions about how planning decisions are made and operationalized, not least because the appraisals are often poorly understood by some key stakeholders. Moreover, Crosby and Wyatt (2016) find that development viability appraisal is being practiced within a poorly specified and misunderstood modelling framework that compromises the equitable distribution of development land value between landowner and society. Finally, McAllister (2017) argues that financial viability appraisals are saturated with intrinsic uncertainty and that there are clear incentives for developers and land owners to bias viability calculations.

\section{Evidence from published appraisals}

In UK practice, when appraising development schemes, many valuers incorporate developer's return as a simple mark-up, either on total development cost or gross development value. In possibly the earliest survey of practice in this field, Marshall and Kennedy (1993) found that $90 \%$ of their sample of development companies, financial institutions and advisors used profit on cost as the return metric and 70\% did not use a cash-flow technique. This was in 1989 and we might expect to see practice move on markedly since that time. Yet Coleman et al. (2012) examined 19 development viability appraisals published between 2007 and 2011 and found that 17 incorporated profit as a margin on cost or revenue, while only one used IRR. All of the appraisals incorporated finance costs under the assumption that development costs were $100 \%$ debt financed. More recently, the London Borough of Southwark reviewed appraisals that were submitted by developers as part of the planning application process (Southwark LBC, 2014). Only two of 19 appraisals expressed developer's return as a target IRR: in both cases, this was $20 \%$ p.a. Sayce et al. (2017) examined some of the latest viability appraisals in London and the development return was not expressed as an IRR in any of the cases.

These findings are perhaps not surprising as the use of IRRs is not encouraged within the financial viability regime that currently underpins the UK planning system. They are treated with suspicion, even by more informed local planning authorities such as Islington, who suggest that "small changes to the development programme and timing of scheme costs and revenues, which may be uncertain at planning stage, can have a large impact on IRR. As such, depending on the quality of information available, the use of an IRR approach when determining development viability as part of the planning process has the potential to be more unstable". This suspicion stems from instances where "costs have been assumed to occur at an unrealistically early stage in the programme while income has been received later than would reasonably be expected". They conclude that this approach is, in some circumstances, "likely to be less reliable" (London Borough of Islington, 2016: 26). This begs the question, less reliable than what?

Why is the distinction between IRR and other forms of developer's return important? Property development projects take time, sometimes many years, and a return that is expressed as a simple mark-up does not reflect the timing of receipt of profit. Therefore, target returns set in this manner might not be adjusted accurately to compensate market participants appropriately for the risks being borne and could lead to incorrect choices between projects. It is hard also to compare returns expressed as a simple cash mark-up with expected returns from investment opportunities in mainstream asset classes, which are quoted typically as per annum return rates.

Presumably, there are development companies and other stakeholders using cash flow based measures of development return such as the IRR, given their widespread adoption in other investment markets. Indeed, references to IRR metrics in UK trade and professional literature 
can be found. For example, Great Portland Estates, a major UK REIT, reported an outturn IRR for one of their flagship developments (33 Margaret Street in London) in their 2016 annual report. The ungeared IRR was $23.5 \%$ p.a. for the six-year scheme, representing a profit on cost of 137\%. Great Portland Estates' reported KPIs for such projects at that time was an ungeared IRR of $18 \%$ p.a. and a profit on cost of $27.1 \%$.

A 2015 Property Week supplement on student accommodation included the quote "I would say 24 months ago they were looking at $20 \%$ IRR on a student development. [Now] I think they're going to need to be comfortable with a 15\% IRR..." ${ }^{3}$ Similarly, IPF (2015) presented a 'riskadjusted returns framework' for large scale residential investment and development, which was, essentially, a set of estimated IRRs for the types of activity associated with different market participants. Housebuilders undertaking development with planning risk were said to seek IRRs of $20 \%$ p.a. and these dropped to $15 \%$ p.a. for schemes without planning risk. Developers / investors constructing and then retaining a scheme long-term were reported to seek IRRs of 10$12 \%$ p.a., while investors looking to invest in existing (i.e. developed) buildings sought $8 \%$ p.a.

Former property consultants DTZ have used IRRs in published UK development appraisals, with a range between $10 \%$ and $25 \%$ p.a. depending on the nature of the scheme. Between 2008 and 2010, area-wide development appraisals undertaken by DTZ included IRR targets as the benchmark (i.e. land value was an input). Property consultants Gerald Eve have also used IRRs in their area-wide development appraisals. In 2013, they produced an appraisal for the City of London and adopted IRR benchmarks of $14 \%$ p.a. for their current value model and 18\% p.a. for their growth model. In both this case and the DTZ cases, the basis for determining the IRRs used was not disclosed.

In other cases, valuers undertaking development viability appraisals have used Argus Developer and reported IRRs alongside other measures of return. In 2009, GVA produced a Strategic Housing Land Availability Assessment for Wyre Forest District Council using residual cash flows to appraise a range of sites subject to a standard set of assumptions regarding building costs and other costs and fees. Developer's profit was assumed to be $20 \%$ of costs, including debt finance. The main appraisal output was residual land value, but IRRs were also reported. ${ }^{4}$ These ranged from $15 \%$ p.a. to $80 \%$ p.a., most likely as a result of the different development periods: bigger schemes took longer and so, given a standard mark-up, the IRR was lower.

Roger Tym and Partners (2013) undertook a series of viability appraisals of hypothetical retail developments in the UK. The results from these are summarised in Table 1. Although schemes A and $C$ were similar in size, value and cost, the IRRs were very different, as they were for $B$ and $D$. It is only on close inspection of the appraisal transcripts that the reason for this is revealed; a substantial letting void was assumed for $\mathrm{A}$ and $\mathrm{B}$, though no mention of this appears in the viability report.

\section{TABLE 1 AROUND HERE}

This example exposes the hazard of relying on a profit-on-cost measure of developer's return. Including a letting void increases costs, but as developer's profit is calculated as a percentage of those costs, there is no obvious penalty (or risk) associated with it. Instead, land value is reduced and the landowner is penalized, while the implied IRR for the developer falls owing to the delay in receiving revenue that is associated with the void. If the developer manages to let the space in schemes A and B on completion, then the IRRs would increase to become similar to

\footnotetext{
3 Property Week Student Accommodation supplement 'Here comes the money', 27 November 2015, p19

${ }^{4}$ These can be estimated by software such as Argus Developer based on the land value result and the revenues and costs used to estimate that value, in a similar manner to the approach discussed in the next section.
} 
those for $\mathrm{C}$ and $\mathrm{D}$. Clearly, a letting void is a development risk and the developer should bear it. Target IRRs might be then adjusted to reflect the additional void risk associated with A and B, but this would suggest that they should be higher and not lower than those for $C$ and $D$.

In planning appeal cases, where one or both parties have used valuation software, implicit IRRs have been revealed. For example, DTZ appraised a 150 dwelling development site at the Holsworthy Showground in Devon in 2010 and assumed a profit on value of 18\% $21.95 \%$ on costs). The Argus-generated IRR was $32 \%$ p.a. Alder King also appraised this site but assumed a $20 \%$ profit on value ( $25 \%$ on costs). Their resultant IRR was $43 \%$ p.a.

Contrastingly, in 2009, in a planning appeal relating to land in Innsworth, Gloucester, 5 the valuer acting for the local planning authority used the IRR as the profit metric in his appraisal. The appraisal itself is not publicly available but, in his decision, the inspector discussed the use of IRR:

"The IRR approach ... has no practical application in circumstances where the investor has no reliable information about the two key items of information, which are time and money. The Appellant has done his best to estimate the amount of, and time at which, money will be spent and the time and rate of income which will be derived. But these are estimates, provided in good faith but subject to a wide range of unknown variables. The effect of this is that the IRR is simply inapplicable in this case. If it were an appropriate tool then the industry would use it. The industry, plainly, does not use it." (Paragraph 111)

In 2012, DVS 6 reviewed Savills' appraisal of the Heygate site in South London and criticised their use of a profit on cost metric. The scheme was very large: approximately 2,400 units over a 13-year development period. DVS recommended an IRR approach and suggested that a range of $15 \%$ to $20 \%$ p.a. for IRR is 'often quoted'.

In 2014, Gerald Eve adopted a target IRR of $20 \%$ for an appraisal of a large residential development site in London (Mount Pleasant Delivery and Sorting Office) comprising 681 dwellings and estimated to take six years to develop. Reviewing this appraisal, DVS adopted two IRRs $-14 \%$ for a non-growth (i.e. present-day values scenario) and 18\% for a growth scenario. Contesting Gerald Eve's appraisal, BPS Chartered Surveyors favoured the more conventional profit-on-cost approach (24\% on private market dwellings blended with $8 \%$ on affordable housing). BPS's argument for doing so was that such a long development period 'favours' the IRR metric. BPS provided an illustration where a 19.6\% IRR for the scheme generates a $28 \%$ profit on cost ( $\mathrm{p} 19)$. They also argued that an IRR cannot differentiate between target returns on the various components of a scheme; in this case, private and affordable housing, which, conventionally, attract markedly different profit-on-cost ratios.

The variation in practice illustrated by these examples, the range in IRRs used or implied in such cases, and the often opaque handling of developer returns, raises two methodological questions when it comes to development appraisal. First, what does the use of a particular cash margin (profit on cost or value) imply about the rate of return that a developer is expected to make from different development opportunities? Second, do the rates of return implied by the use of cash margins exhibit logical relationships with the timescales, costs and risks present in different scenarios? These questions are addressed in the remainder of this paper through theoretical modelling of developer returns. This is with the broader purpose of reflecting on what is an 'appropriate' developer return in different situations.

\footnotetext{
${ }^{5}$ APP/G1630/A/09/2097181.

${ }^{6}$ DVS, or District Valuer Services, are part of the Valuation Office Agency, a government agency, and they provide valuation services to UK public sector organisations.
} 


\section{Method}

The traditional residual valuation model as applied in UK practice takes inputs for the value of a completed scheme, the estimated costs of constructing that scheme, and other costs, and uses these inputs to estimate either the profit a developer will make when the land price is known or the value of a piece of land given an assumption about the profit a developer should seek. In this paper, the focus is the second of these alternatives. When estimating land value, the developer's profit is expressed as a simple mark-up, but this could represent very different IRRs dependent on variables such as the development period and the scale of costs relative to revenues. This paper recasts a number of residual appraisals in cash flow form, testing a variety of inputs to explore the range of IRRs that result.

A simple residual valuation of a development site is illustrated below. As noted by Coleman et al. (2012), some steps in this method vary from appraisal practices advocated in corporate finance. The assumed development value (on completion) is $£ 2 \mathrm{~m}$, construction costs are $£ 1 \mathrm{~m}$ and the development period is two years. The residual valuation model assumes that the development costs are $100 \%$ debt financed and, to reflect incremental drawdown of debt during the building phase, a simplifying assumption is made that these costs are incurred halfway through the period. This means that interest is compounded over one year on the construction costs. The developer's required profit is assumed to be $15 \%$ of all development costs (building, finance and land costs). Using this information, the method produces a land value estimate of $£ 625,062$.

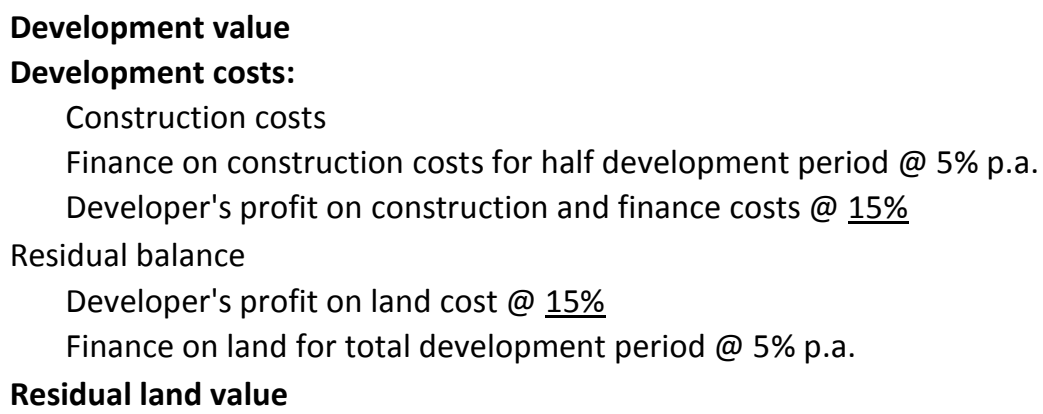

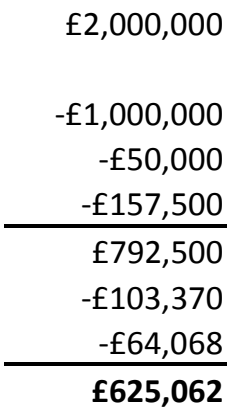

It is assumed that the development value is realised at the end of the development period, from which construction costs, interest on these costs and an allowance for profit are then deducted. The residual balance that results from this calculation represents an amount available for land purchase as at the end of the development period; a sum that must cover land acquisition costs, finance costs and an allowance for profit on land costs. This explains the approach taken in the final few rows of the calculation, which involves discounting the post-profit residual balance back to the present.

To recast this as a project cash flow, only three figures are needed: land cost, construction cost and development value. No assumption is required as to the eventual mix of funding, although flows to debt and equity could be computed if such an assumption is made. The cash flow is shown in panel A of Table 2. The IRR for this cash flow represents the expected return rate for the project as implied by the residual method. With interest costs stripped out, profit as a percentage of costs rises from $15 \%$ to $23 \%$. In comparison, the pre-finance IRR is $16 \%$ per annum. It is the behaviour of this figure in relation to changes in variables such as project length, required profit and the ratio of costs to final value that is of interest. 
The rate of return on the developer's equity could be higher if debt is used, but it is contingent on how much is borrowed and at what rate. It is unlikely that a bank would lend $100 \%$ of development costs in practice, despite this being a standard assumption in the traditional residual approach. In panel B of Table 2, calculation of the equity cash flow is shown assuming an interest rate of 5\% per annum on funds borrowed, a loan-to-cost ratio of $60 \%$ and an equal sharing of costs between bank and developer at each stage. Since the project IRR is greater than the cost of debt in this example, the equity IRR (at 31\% p.a.) is higher than its project level equivalent. ${ }^{7}$ However, this figure is more sensitive to changes in the inputs used, reflecting the impact of gearing.

To compute the IRR implied by different residual valuations, it might be assumed that a trial and error approach is necessary, with each cash flow being unique and specific to the scenario being considered. However, provided that expected revenue is greater than expected costs (so that a positive land value exists), an analytical solution is possible for many basic residual valuations as there are only three time points and two time intervals involved. Discussion of this solution allows the key factors affecting the implied IRR to be identified. Typically, there is an initial outflow (land) assumed at time 0 , a subsequent outflow (construction) at time 1 and then a final inflow (revenue) at time 2. The relationship between the three is shown in equation 2 .

$$
\mathrm{R}=\mathrm{L}(1+\mathrm{r})^{2}+\mathrm{C}(1+\mathrm{r})
$$

Where $\mathrm{R}=$ revenue, $\mathrm{L}=$ land cost, $\mathrm{C}=$ construction cost and $\mathrm{r}=$ the internal rate of return that reconciles the timing of the inflows and outflows. Equation 2 shows that return must be earned over two time intervals for the capital invested in land and one interval for the capital invested in construction. Figures for R, $\mathrm{L}$ and $\mathrm{C}$ can be extracted from the residual valuation, but the rate of return is unknown. In order to solve for $r$, equation 2 can be rewritten, which shows that the problem has the form of a quadratic equation:

$$
L(1+r)^{2}+C(1+r)-R=0
$$

The standard formula for solving quadratic equations could be employed at this point and there will be two possible solutions for $(1+r)$ in most cases, although only one of these is likely to be plausible in terms of representing the IRR. Note, though, that IRR is affected not so much by the absolute figures for $\mathrm{L}, \mathrm{C}$ and $\mathrm{R}$ as by the relativities between them. So the IRR would be the same when, say, land cost is $£ 4$ million, construction is $£ 5$ million and revenue is $£ 10$ million as when land, construction and revenue are $£ 8$ million, $£ 10$ million and $£ 20$ million, respectively. Hence, we define $\mathrm{p}$ as the ratio between construction costs and land costs, and $\mathrm{q}$ as the ratio between revenues and land costs. Dividing through each term in equation 3 by L yields:

$$
(1+r)^{2}+p(1+r)-q=0
$$

Both $\mathrm{p}$ and $\mathrm{q}$ can then be inserted into the standard quadratic equation formula so that $(1+\mathrm{r})$ can be found as follows:

$$
(1+r)=\frac{-p \pm \sqrt{p^{2}+4 q}}{2}
$$

Using the example above where the land cost was $£ 625,062$, construction costs were $£ 1$ million and revenue was $£ 2$ million, $\mathrm{p}=1.6, \mathrm{q}=3.2$ and so $\mathrm{r}=15.96 \%$ per period, based on the positive root for equation 5 . This result matches the per annum IRR given that the development period in this case is two years. Yet what if the development took one, three or any other number of

\footnotetext{
${ }^{7}$ Meanwhile, profit-on-cost (at 19\%) lies between the figure from the residual valuation (which assumes $100 \%$ debt finance) and the figure from the project cash flow (which does not include debt).
} 
years to be built? Provided that the construction costs fall halfway through the period, there is no need to alter this approach, but the answer from equation 5 must be rescaled so that it can be compared across projects or scenarios of different length. This can be done as follows:

$$
(1+r)^{(1 / 0.5 t)}-1=\text { IRR p.a. }
$$

The key input variables are final development value, construction cost, development period, developer's profit, and finance rate. These will be entered into the basic residual model to determine a set of land values. In turn, these land values are input into a cash flow model alongside construction cost and development value in order to calculate the corresponding IRRs. The modelled input parameters are shown in table 3. Two output IRRs are computed; an ungeared (project) IRR and a geared (equity) IRR. As per the earlier example, a loan-to-cost ratio of $60 \%$ is used to generate the equity cash flow and geared IRR.

\section{TABLE 3 AROUND HERE}

\section{Findings}

Tables 4 and 5 show ungeared (project) and geared (equity) per annum IRRs respectively for the range of input parameters specified in Table 3.

Looking at Table 4 first, the two main drivers of variation between a simple profit on cost and the project IRR are the length of time a development takes and the ratio of costs to value, while finance rates have very little impact. The development period has the most impact on the IRR when tested against a fixed return on cost ratio. If the same proportionate reward against a given cash outlay is spread over more years, then the associated IRR will naturally fall as the time period lengthens. There is a counter-effect in that, the longer the period, the higher the interest charges in the residual model and the lower the residual land value. A reduced land value will then reduce the initial costs of the scheme, but this is more than offset by the normal discounting of future revenue flows, so as the development period gets longer, the IRRs reduce. This pattern is in contrast to what literature from corporate finance suggests in regard to the behaviour of required rates of return; that these should, all else equal, be higher with longer duration projects (see Cornell, 1999).

The project IRR most closely mimics the profit on cost for schemes of around two to three years; shorter schemes have higher IRRs than the profit on cost measure and longer schemes produce lower IRRs. The central pane in table 4 shows an IRR of $20 \%$ when the development period is two years, profit on costs is $20 \%$ and the finance rate is $5 \%$ per annum. This falls to between $15 \%$ and $10 \%$ as the development period increases from three to five years.

\section{TABLE 4 AROUND HERE}

As the ratio between construction costs and development value gets higher, so does the IRR because, relatively, the initial outlay on land is getting lower. As land value becomes a larger share of the development cost, the IRR reduces because there is more cost incurred the start of the development period.

These patterns help to corroborate, if not explain, the low average achieved IRR for the sample of UK development schemes studied by IPD (2010). IPD examined c. 3,500 UK development schemes completed between 1983 and 2008, and found the median return rate to be only $7 \%$ per annum, less than that offered by standing investments over the same period. If institutional investors in general tend to participate in larger and longer development projects that are sited 
in higher value locations, then this is consistent with the relatively low return rates suggested in certain parts of Table 4. However, it is not clear how institutional investors are setting their return expectations at the start of such schemes, whether achieved return rates are consistent with those expectations, and whether lower per annum target rates of return would be rational in such situations. These questions require further investigation, particularly given the counterarguments in the corporate finance literature. For example, deeper analysis of the IPD (now MSCI) UK development returns data is necessary to see precisely what impact the length of developments had on their outcome.

When finance rates increase, the IRR in Table 4 increases as well because a higher anticipated finance rate translates into a higher cost in the residual model, resulting in a lower site value and, presumably, a lower bid for the land as a consequence. As finance plays no part in the cash flow model, the project IRR then increases because the same cash flow is based on a slightly lower initial land input: within this analysis, that increase is virtually one-for-one across all of the permutations. This result might seem counter-intuitive, but it is consistent with developers seeking higher returns from schemes in markets where the opportunity cost of capital is greater and, in periods where cost of borrowing is higher, developers would seek opportunities that offered a higher rate of return.

In practical terms, the $100 \%$ debt finance assumption in the residual model is not realistic. The reality is that developers may well debt finance at least some of the costs, including site acquisition, and a higher IRR on the remaining equity would be required as a result. This then increases further as the level of gearing increases. In the project cash flow, the effects of finance are (and should be) ignored, but this leaves the question of what the residual method implies about the rates of return received by developers once realistic assumptions about project gearing are applied.

Therefore, the analysis above is extended by assuming that the project expected costs in each and every scenario are split between developer (equity) and lender (debt), with a 60\% loan-tocost ratio used so that costs are split 60/40 between lender and developer, while the assumed finance rate determines interest payments to the lender. The IRR is then recalculated for the equity cash flow in each case in order to test the possible effects on equity rates of return from varying timescales, costs, finance rates and profit assumptions. The results of this analysis are set out in Table 5. The equity IRRs are higher than the corresponding project IRRs, as expected. In fact, the $60 \%$ loan-to-cost ratio approximately doubles the project IRR.

\section{TABLE 5 AROUND HERE}

The impact of gearing on both absolute and relative increases in IRR is the same: the longer the scheme the less the impact. A one-year scheme has a very high project IRR relative to the profit on costs and this increases dramatically when calculated as an equity IRR on a $60 \%$ loan-to-cost ratio. For example, at a developer's profit at $20 \%$ of costs, finance at $5 \%$ and a $50 \%$ cost-tovalue ratio, the project IRR over one year increases from $36 \%$ to an equity IRR of $86 \%$. On a sixyear scheme it increases from $10 \%$ to $16 \%$. Nonetheless, the basic conclusions about the impact of timescale and of the cost/value relationship on implied per annum return rates given the use of standard profit metrics remain the same.

We find, then, that the two main drivers of variation between profit-on-cost and project IRR identified in this paper are (a) development period and (b) land cost to development value ratio. Holding profit-on-cost constant, as the development period increases the project IRR decreases, and as land value as a proportion of development value decreases the project IRR increases. Mathematically, these results are unsurprising. The longer it takes to receive revenue, the lower the IRR, and the smaller the upfront land cost, the higher the IRR. When the equity IRR is modelled, the resulting effects are the same but magnified due to the gearing effect. However, 
are these effects rational? Should expected risk (and hence the risk premium component of a target IRR) increase as development period increases? Are larger and longer development schemes more risky or do they offer more opportunity to phase and exercise optionality, thus mitigating risk? Is this sort of risk mitigation more likely in relation to low density housing developments compared to high density, single-building developments? These issues cannot be answered through the mathematical modelling, but are relevant to a wider debate about the rates of return that different development opportunities should be expected to offer.

Of course, there are more than two forces on the IRR and it may be that a matrix of cost and revenue influences is required to understand their magnitude and direction. In the model presented here, we have generalised variability in the cost and revenue inputs as a simple ratio between construction costs and development value. Where the ratio is low (say 25\%), revenue inputs such as sale prices, rents and particularly yields will have a larger influence than when the ratio is high (say 75\%). Also, many developments will have pre-construction periods and letting voids within the overall development period. This has been handled in here by assuming land acquisition takes place at the start, construction costs are incurred as a lump sum midway through and revenue is received at the end of the development period. Refinement of these assumptions is something to explore.

One thing we can be fairly confident of is that, because of the inability to handle time properly, a single figure or narrow range for profit-on-cost is incapable of reflecting variations in required return adequately. This raises the question of whether one can recalculate the profit-on-cost input for a simple residual given a consistent target IRR across project types. The results of such an analysis are shown in Table 6, using a fixed IRR target of $20 \%$ per annum. The findings are consistent with the insights above. As the development period lengthens, a higher profit on cost is needed if a consistent target IRR is to be maintained. The profit-on-cost would also need to increase as the ratio of construction costs to final development value decreases. This is to compensate the fact that a greater share of the total costs are upfront costs. However, it falls as the finance rate increases owing the effect that this rate has on the assumed land bid and thus the land cost that would enter the cash flow.

\section{TABLE 6 AROUND HERE}

These statements do not imply that the target IRR should remain constant across different types of project any more than the profit-on-cost should stay fixed, but it again highlights the need for closer scrutiny of the profit assumption by market participants, appraisers and other interested parties.

\section{Conclusions}

Estimation of required rates of return for real estate development projects has received less attention than the comparable process for real estate investments. Arguably, required profit in the UK case owes more to rules of thumb than any serious analysis. The rule of thumb requirements set out in this paper are based on case studies of individual project returns together with literature and market commentary on development returns. Case studies of individual schemes have become more plentiful in the UK due to the relatively new requirement to assess development viability in the English planning system. Although this enables appraisal techniques and assumptions about profit to be studied in more detail, it is still well below the level of data required to undertake a full analysis of development returns and how they are established. Subject to these limitations, our examination reveals large fluctuations in reported IRRs that appear to flow from the use of standard profit-on-cost inputs. Yet policy requirements act against the use, and therefore publication, of IRRs for development appraisal, preferring the use of simple profit on cost or value measures. 
Accepting the argument from the capital budgeting literature that IRR is a more rational return metric than cash-based measures, as it accounts for the time value of money and that it should increase for longer projects, we modelled the IRRs that would be implied from use of a traditional residual valuation method and typical profit-on-cost requirements. The findings are set out in the previous section but two key points can be made. First, if simple profit-on-cost measures are not changed adequately for projects of different lengths, then the implied required return rate varies substantially and reduces as the project gets longer. This variation is particularly marked for projects between one and three years in length, but stabilizes when projects pass three years in length. Second, high land values (where construction costs are a low percentage of development values) result in lower IRRs if the profit-on-cost assumption is not altered. This reflects the relative timing of expenditures on land and construction during a project's life.

The approach to the analysis was to first hold the developer's profit percentage constant and identify land value from the residual model. The revenues, land cost and construction cost from the residual model were then fed into a cash flow model, from which the corresponding IRRs were identified and compared. Some inputs to the residual model were then varied, which altered the land value and impacted on the implied cash flow and IRR in turn. This may appear to be a somewhat circular process, but the point is to identify what target return rate would be needed in a cash flow model to generate the same residual land value. The question then is whether the patterns implied by the results are rational and whether the simple residual can pick up any of the nuances in required return rate that ought to exist between different types and lengths of project.

Many questions remain about the choice of target rates of return for development projects, which we have not addressed in this paper. Paucity of information and a lack of transparency surrounding the information that does exist may influence the choice of valuation models adopted in practice. From an investigation of development valuations that are in the public domain, our research finds that traditional residual valuation models continue to be used. The way in which the required return is expressed and the level at which it is set would appear to be based on simple ratio measures rather than an annual internal rate of return. This may be a consequence of the information-poor environment within which development valuations take place. The resultant IRRs that are implied by these profit ratios behave counter-intuitively; falling as project duration increases to the point that they would yield lower rates of return than those normally obtainable from standing investments. Moreover, use of simple profit ratios means that it is not possible to compare required returns or risk premiums for individual development projects with other investment opportunities.

Much of the evidence on which this research is based comes from the development viability appraisals that are undertaken within the UK planning system and the UK government believes that there is an excessive amount of "gaming" in that process (DCLG, 2017). If developers can prove that land has a high cost, they can use that information to remove any liability to use development profits for local planning authority obligations. Our results suggest that, within the viability process, developers may be incentivised to use simple residual models with basic profit measures for shorter developments and IRRs for longer developments in their assessments of land value. We have not yet investigated the hypothesis that the policy aspects of development viability are hiding a more informed and sophisticated modelling framework within the real estate development industry.

If the use of cash flow analysis and target return rates for assessing land value is more widespread than public domain examples and literature suggests, what target rates of return are developers using in practice? Even though the literature suggests that rates of return should be stable or even increase in line with project duration, do developers anticipate lower 
rates of return from longer developments and developments with high initial land costs? If the available evidence does capture market practice for setting return requirements, what are the implications for the operation of land markets and for development activity? Does simplistic use of profit-on-cost distort market behaviour and why hasn't arbitrage led to more rational targets and practices being adopted? Further research will consider these issues.

\section{References}

Brown, G and Matysiak, G. (2000) Real Estate Investment: a Capital Budgeting Approach, Financial Times Prentice Hall: Harlow.

Campbell, J.Y. and Mei, J. (1993) Where do betas come from? Asset price dynamics and the sources of systematic risk. Review of Financial Studies 6(3), 567- 92.

Clayton, J., Ling, D. and Naranjo, A. (2009) Commercial real estate valuation: fundamentals versus investor sentiment. Journal of Real Estate Finance and Economics. 38. 5-37.

Coleman, C., Crosby, N., McAllister, P. and Wyatt, P. (2012) Development Appraisal in Practice: Some Evidence from the UK Planning System, Journal of Property Research, 30(2), 144165.Cornell, B. (1999) Risk, Duration, and Capital Budgeting: New Evidence on Some Old Questions. Journal of Business, 72(2), 183-200.

Crosby, N., McAllister, P. and Wyatt, P. (2013) Fit for planning? An evaluation of the application of development viability appraisal models in the UK planning system, Environment and Planning $B, 40,3-22$

Crosby, N. and Wyatt, P. (2016) Financial viability appraisals for site-specific planning decisions in England, Environment and Planning C: Policy and Space. 34(8), 1716-38

Crosby, N., Jackson, C., \& Orr, A. (2016) Refining the real estate pricing model. Journal of Property Research, 33(4), 332-358.

DCLG (2017) Planning for the right homes in the right places: consultation proposals. Department for Communities and Local Government.

DCLG (2007) The Callcutt Review of Housing Delivery. Department for Communities and Local Government.

Geltner, D. and Miller, N. (2000) Commercial Real Estate Analysis and Investments, SouthWestern University Press.

Graham, J. R. and Harvey, C. R. (2001) The theory and practice of corporate finance: evidence from the field, Journal of Financial Economics, 60, 187-243.

Hutchison, N., Lizieri, C., MacGregor, B., Mansley, N., Portlock, R., Schulz, R. and Zhao, Y. (2017) An Investigation of Hurdle Rates in the Real Estate Investment Process. London: Investment Property Forum.

IPD (2010) IPD Development Performance. London: Investment Property Databank.

IPF (2015) Mind the viability gap: achieving more large-scale, build-to-rent housing. London: Investment Property Forum.

London Borough of Islington (2016) Development Viability. Supplementary Planning Document. January 2016.

Marshall, P. and Kennedy, C. (1993) Development valuation techniques, Journal of Property Vaulation and Investment, 11(1), 57-66.

McAllister, P., Wyatt, P. and Coleman, C. (2013) Fit for policy: some evidence on the application of development viability models in the United Kingdom planning system, Town Planning Review, 80(4), 495-522

McAllister, P., Street, E. and Wyatt, P. (2015) Governing calculative practices: an investigation of development viability modelling in the English planning system, Urban Studies, DOI: 10.1177/0042098015589722

McAllister, P. (2017) The calculative turn in land value capture: Lessons from the English planning system, Land Use Policy, 63, 122-129

Roger Tym and Partners 2013 Chelmsford City Council CIL Non-Residential Evidence Base Update. 
Sayce et al (2017) Viability and the Planning System: The Relationship Between Economic Viability Testing, Land Values and Affordable Housing in London, Kingston University, Ramidus, Royal Agricultural University and the University of Reading.

Southwark London Borough Council (2014) Southwark's Community Infrastructure Levy (CIL): LBS survey of viability appraisals submitted with planning applications, December 2014. 
Table 1: IRRs implied by viability appraisals for hypothetical retail schemes

\begin{tabular}{|c|l|c|c|c|c|c|c|c|}
\hline & \multicolumn{1}{|c|}{ Type } & $\begin{array}{c}\text { Size } \\
(\mathbf{m} 2)\end{array}$ & NDV (E) & $\begin{array}{c}\text { Total } \\
\text { costs (E) }\end{array}$ & $\begin{array}{c}\text { Profit } \\
(\boldsymbol{E})\end{array}$ & $\begin{array}{c}\text { Profit } \\
\text { on cost } \\
\mathbf{( \% )}\end{array}$ & IRR & $\begin{array}{c}\text { Letting void } \\
\text { finance cost } \\
(\boldsymbol{E})\end{array}$ \\
\hline A & Comparison & 1,000 & $2,861,161$ & $2,384,300$ & 476,861 & $20 \%$ & $\begin{array}{c}19.54 \\
\%\end{array}$ & 154,690 \\
\hline B & Comparison & 200 & 663,789 & 553,158 & 110,632 & $20 \%$ & $\begin{array}{c}19.67 \\
\%\end{array}$ & 35,778 \\
\hline C & Convenience & 1,000 & $3,123,555$ & $2,602,963$ & 520,593 & $20 \%$ & $\begin{array}{c}38.43 \\
\%\end{array}$ & 0 \\
\hline D & Convenience & 215 & 639,585 & 532,988 & 106,598 & $20 \%$ & $\begin{array}{c}40.14 \\
\%\end{array}$ & 0 \\
\hline
\end{tabular}

Source: Roger Tym and Partners (2013)

Table 2: Project cash flow implied by example residual valuation

\begin{tabular}{|c|c|c|c|}
\hline \multicolumn{4}{|l|}{ Panel A: Implied project cash flow } \\
\hline & YEAR 0 & YEAR 1 & YEAR 2 \\
\hline Development value & & & $2,000,000$ \\
\hline Development costs & $-625,062$ & $-1,000,000$ & \\
\hline Project cash flow & $-625,062$ & $-1,000,000$ & $2,000,000$ \\
\hline Implied internal rate of return p.a. & & & $16.0 \%$ \\
\hline \multicolumn{4}{|c|}{ Panel B: Equity cash flow with loan at $60 \%$ LTC } \\
\hline & YEAR 0 & YEAR 1 & YEAR 2 \\
\hline Opening balance for loan & 0 & 375,037 & 993,789 \\
\hline Interest payment at $5 \%$ p.a. & 0 & 18,752 & 49,689 \\
\hline Drawdown & 375,037 & 600,000 & 0 \\
\hline Closing balance for loan & 375,037 & 993,789 & $1,043,478$ \\
\hline Equity cash flow & $-250,025$ & $-400,000$ & 956,522 \\
\hline Implied internal rate of return p.a. & & & $31.3 \%$ \\
\hline
\end{tabular}

Table 3: Input parameters

\begin{tabular}{|l|c|c|c|c|}
\hline Input & Base case & Parameters & $\begin{array}{c}\text { Increment } \\
\text { size }\end{array}$ & $\begin{array}{c}\text { Number of } \\
\text { increments }\end{array}$ \\
\hline Construction cost as \% of development value & $50 \%$ & $25 \%-75 \%$ & $25 \%$ & 3 \\
\hline Finance rate (\% p.a.) & $5 \%$ & $6 \%-7 \%$ & $1 \%$ & 3 \\
\hline Development period & 2 years & $1-6$ years & 1 year & 6 \\
\hline Developer's profit (\% costs) & $15 \%$ & $15 \%-25 \%$ & $5 \%$ & 3 \\
\hline
\end{tabular}




\section{Table 4: Ungeared (project) IRRs}

\begin{tabular}{|c|c|c|c|c|c|c|c|c|c|c|c|c|c|c|c|c|c|c|c|c|}
\hline & \multicolumn{6}{|c|}{ Developer's profit on cost - $15 \%$} & \multicolumn{6}{|c|}{ Developer's profit on cost - $20 \%$} & \multicolumn{6}{|c|}{ Developer's profit on cost - $25 \%$} \\
\hline & & & \multicolumn{6}{|c|}{ Development period (years): } & \multicolumn{6}{|c|}{ Development period (years): } & \multicolumn{6}{|c|}{ Development period (years): } \\
\hline & & & 1 & 2 & 3 & 4 & 5 & 6 & 1 & 2 & 3 & 4 & 5 & 6 & 1 & 2 & 3 & 4 & 5 & 6 \\
\hline \multicolumn{21}{|c|}{ Construction cost as $\%$ of development value - $25 \%$} \\
\hline \multirow{3}{*}{ 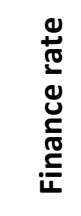 } & \multirow{3}{*}{$\begin{array}{l}\text { } \\
\stackrel{0}{0} \\
\stackrel{0}{0} \\
\stackrel{0}{0}\end{array}$} & $5 \%$ & $24 \%$ & $14 \%$ & $11 \%$ & $9 \%$ & $9 \%$ & $8 \%$ & $30 \%$ & $17 \%$ & $13 \%$ & $11 \%$ & $10 \%$ & $9 \%$ & $37 \%$ & $20 \%$ & $15 \%$ & $12 \%$ & $11 \%$ & $10 \%$ \\
\hline & & $6 \%$ & $25 \%$ & $15 \%$ & $12 \%$ & $10 \%$ & $10 \%$ & $9 \%$ & $31 \%$ & $18 \%$ & $14 \%$ & $12 \%$ & $11 \%$ & $10 \%$ & $38 \%$ & $21 \%$ & $16 \%$ & $13 \%$ & $12 \%$ & $11 \%$ \\
\hline & & $7 \%$ & $26 \%$ & $16 \%$ & $13 \%$ & $12 \%$ & $11 \%$ & $10 \%$ & $33 \%$ & $19 \%$ & $15 \%$ & $13 \%$ & $12 \%$ & $11 \%$ & $39 \%$ & $22 \%$ & $17 \%$ & $14 \%$ & $13 \%$ & $12 \%$ \\
\hline \multicolumn{21}{|c|}{ Construction cost as $\%$ of development value - $50 \%$} \\
\hline \multirow{3}{*}{ 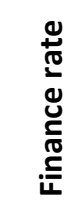 } & \multirow{3}{*}{$\begin{array}{l}\text { } \\
\stackrel{0}{0} \\
\stackrel{0}{0} \\
\stackrel{0}{0}\end{array}$} & $5 \%$ & $27 \%$ & $16 \%$ & $12 \%$ & $10 \%$ & $9 \%$ & $9 \%$ & $36 \%$ & $20 \%$ & $15 \%$ & $12 \%$ & $11 \%$ & $10 \%$ & $45 \%$ & $24 \%$ & $17 \%$ & $14 \%$ & $12 \%$ & $11 \%$ \\
\hline & & $6 \%$ & $29 \%$ & $17 \%$ & $13 \%$ & $12 \%$ & $10 \%$ & $10 \%$ & $38 \%$ & $21 \%$ & $16 \%$ & $13 \%$ & $12 \%$ & $11 \%$ & $47 \%$ & $25 \%$ & $18 \%$ & $15 \%$ & $14 \%$ & $12 \%$ \\
\hline & & $7 \%$ & $30 \%$ & $18 \%$ & $15 \%$ & $13 \%$ & $12 \%$ & $11 \%$ & $39 \%$ & $22 \%$ & $17 \%$ & $14 \%$ & $13 \%$ & $12 \%$ & $48 \%$ & $26 \%$ & $20 \%$ & $17 \%$ & $15 \%$ & $14 \%$ \\
\hline \multicolumn{21}{|c|}{ Construction cost as $\%$ of development value - $75 \%$} \\
\hline \multirow{3}{*}{ 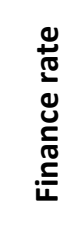 } & \multirow{3}{*}{ 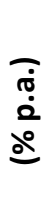 } & $5 \%$ & $35 \%$ & $19 \%$ & $14 \%$ & $12 \%$ & $11 \%$ & $10 \%$ & $47 \%$ & $25 \%$ & $18 \%$ & $15 \%$ & $*$ & $*$ & $61 \%$ & $31 \%$ & $*$ & $*$ & $*$ & $*$ \\
\hline & & $6 \%$ & $36 \%$ & $20 \%$ & $16 \%$ & $13 \%$ & $12 \%$ & $*$ & $49 \%$ & $26 \%$ & $19 \%$ & $*$ & $*$ & $*$ & $63 \%$ & $32 \%$ & $*$ & $*$ & $*$ & $*$ \\
\hline & & $7 \%$ & $38 \%$ & $22 \%$ & $17 \%$ & $15 \%$ & $13 \%$ & $*$ & $50 \%$ & $28 \%$ & $21 \%$ & $*$ & $*$ & $*$ & $65 \%$ & $*$ & $*$ & $*$ & $*$ & $*$ \\
\hline
\end{tabular}

* Negative residual land value 
Table 5: Geared (equity) IRRs (60\% loan-to-cost ratio)

\begin{tabular}{|c|c|c|c|c|c|c|c|c|c|c|c|c|c|c|c|c|c|c|c|c|}
\hline & & & \multicolumn{6}{|c|}{ Developer's profit on cost - 15\% } & \multicolumn{6}{|c|}{ Developer's profit on cost - $20 \%$} & \multicolumn{6}{|c|}{ Developer's profit on cost - $25 \%$} \\
\hline & & & \multicolumn{6}{|c|}{ Development period (years): } & \multicolumn{6}{|c|}{ Development period (years): } & \multicolumn{6}{|c|}{ Development period (years): } \\
\hline & & & 1 & 2 & 3 & 4 & 5 & 6 & 1 & 2 & 3 & 4 & 5 & 6 & 1 & 2 & 3 & 4 & 5 & 6 \\
\hline \multicolumn{21}{|c|}{ Construction cost as $\%$ of development value - $25 \%$} \\
\hline \multirow{3}{*}{ 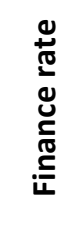 } & & $5 \%$ & $52 \%$ & $26 \%$ & $19 \%$ & $15 \%$ & $13 \%$ & $12 \%$ & $68 \%$ & $33 \%$ & $23 \%$ & $18 \%$ & $16 \%$ & $14 \%$ & $85 \%$ & $40 \%$ & $27 \%$ & $21 \%$ & $18 \%$ & $16 \%$ \\
\hline & $\check{\dot{\sigma}}$ & $6 \%$ & $53 \%$ & $28 \%$ & $20 \%$ & $16 \%$ & $14 \%$ & $13 \%$ & $70 \%$ & $34 \%$ & $24 \%$ & $20 \%$ & $17 \%$ & $15 \%$ & $87 \%$ & $41 \%$ & $28 \%$ & $22 \%$ & $19 \%$ & $17 \%$ \\
\hline & $\lesssim$ & $7 \%$ & $55 \%$ & $29 \%$ & $21 \%$ & $18 \%$ & $15 \%$ & $14 \%$ & $72 \%$ & $36 \%$ & $26 \%$ & $21 \%$ & $18 \%$ & $16 \%$ & $89 \%$ & $42 \%$ & $30 \%$ & $24 \%$ & $20 \%$ & $18 \%$ \\
\hline \multicolumn{21}{|c|}{ Construction cost as \% of development value - $50 \%$} \\
\hline \multirow{3}{*}{ 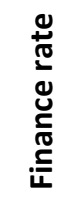 } & \multirow{3}{*}{ 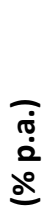 } & $5 \%$ & $64 \%$ & $31 \%$ & $22 \%$ & $18 \%$ & $15 \%$ & $14 \%$ & $86 \%$ & $40 \%$ & $28 \%$ & $22 \%$ & $18 \%$ & $16 \%$ & $110 \%$ & $49 \%$ & $33 \%$ & $26 \%$ & $21 \%$ & $19 \%$ \\
\hline & & $6 \%$ & $65 \%$ & $33 \%$ & $23 \%$ & $19 \%$ & $16 \%$ & $15 \%$ & $88 \%$ & $42 \%$ & $29 \%$ & $23 \%$ & $20 \%$ & $17 \%$ & $112 \%$ & $51 \%$ & $35 \%$ & $27 \%$ & $23 \%$ & $20 \%$ \\
\hline & & $7 \%$ & $67 \%$ & $34 \%$ & $25 \%$ & $20 \%$ & $18 \%$ & $16 \%$ & $90 \%$ & $43 \%$ & $30 \%$ & $24 \%$ & $21 \%$ & $19 \%$ & $115 \%$ & $52 \%$ & $36 \%$ & $29 \%$ & $24 \%$ & $22 \%$ \\
\hline \multicolumn{21}{|c|}{ Construction cost as $\%$ of development value - $75 \%$} \\
\hline \multirow{3}{*}{ 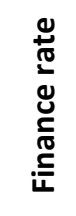 } & & $5 \%$ & $84 \%$ & $40 \%$ & $28 \%$ & $22 \%$ & $19 \%$ & $17 \%$ & $121 \%$ & $54 \%$ & $36 \%$ & $28 \%$ & $*$ & $*$ & $165 \%$ & $69 \%$ & $*$ & $*$ & $*$ & $*$ \\
\hline & के & $6 \%$ & $87 \%$ & $42 \%$ & $29 \%$ & $24 \%$ & $20 \%$ & $*$ & $123 \%$ & $56 \%$ & $38 \%$ & $*$ & $*$ & $*$ & $169 \%$ & $72 \%$ & * & $*$ & $*$ & $*$ \\
\hline & $\lesssim$ & $7 \%$ & $89 \%$ & $43 \%$ & $31 \%$ & $25 \%$ & $23 \%$ & $*$ & $126 \%$ & $58 \%$ & $40 \%$ & $*$ & $*$ & $*$ & $173 \%$ & $*$ & $*$ & $*$ & $*$ & $*$ \\
\hline
\end{tabular}

* Negative residual land value 
Table 6: Variation in developer's profit given a fixed IRR of $\mathbf{2 0 \%}$

\begin{tabular}{|c|c|c|c|c|c|c|c|}
\hline & \multicolumn{6}{|c|}{ Development Period (years) } \\
\hline & & 1 & 2 & 3 & 4 & 5 & 6 \\
\hline \multicolumn{8}{|c|}{ Construction cost as $\%$ of development value - $25 \%$} \\
\hline \multirow{3}{*}{$\begin{array}{c}\text { Finance } \\
\text { rate } \\
\text { (\% p.a.) }\end{array}$} & $5 \%$ & $12 \%$ & $25 \%$ & $39 \%$ & $54 \%$ & $69 \%$ & $83 \%$ \\
\hline & $6 \%$ & $11 \%$ & $23 \%$ & $36 \%$ & $49 \%$ & $62 \%$ & $76 \%$ \\
\hline & $7 \%$ & $10 \%$ & $21 \%$ & $33 \%$ & $44 \%$ & $57 \%$ & $69 \%$ \\
\hline \multicolumn{8}{|c|}{ Construction cost as \% of development value - $50 \%$} \\
\hline \multirow{3}{*}{$\begin{array}{c}\text { Finance } \\
\text { rate } \\
\text { (\% p.a.) }\end{array}$} & $5 \%$ & $10 \%$ & $20 \%$ & $30 \%$ & $40 \%$ & $49 \%$ & $56 \%$ \\
\hline & $6 \%$ & $9 \%$ & $19 \%$ & $28 \%$ & $37 \%$ & $45 \%$ & $52 \%$ \\
\hline & $7 \%$ & $9 \%$ & $17 \%$ & $26 \%$ & $34 \%$ & $41 \%$ & $47 \%$ \\
\hline \multicolumn{8}{|c|}{ Construction cost as $\%$ of development value - $75 \%$} \\
\hline \multirow{3}{*}{$\begin{array}{c}\text { Finance } \\
\text { rate } \\
\text { (\% p.a.) }\end{array}$} & $5 \%$ & $8 \%$ & $16 \%$ & $22 \%$ & $*$ & $*$ & $*$ \\
\hline & $6 \%$ & $8 \%$ & $15 \%$ & $21 \%$ & $*$ & $*$ & $*$ \\
\hline & $7 \%$ & $7 \%$ & $12 \%$ & $19 \%$ & $*$ & $*$ & $*$ \\
\hline
\end{tabular}

* Negative residual land value 